\title{
Facet Dislocation Fractures of Subaxial Cervical Spine: A Treatment Algorithm for Surgical Approach Decision
}

\section{Subaksiyel Servikal Omurganın Faset Dislokasyon Fraktürleri: Cerrahi Yaklaşım Kararı için Tedavi Algoritması}

\author{
(D) Barış Özöner1,2, (D) Levent Aydın³, (D) Songül Meltem Can³, (D) Ahmet Murat Müslüman³, \\ ${ }^{1}$ Bahçeşehir University Faculty of Medicine, Department of Neurosurgery, İstanbul, Turkey \\ 2Erzincan Binali Yıldırım University Faculty of Medicine, Department of Neurosurgery, Erzincan, Turkey \\ ${ }^{3}$ University of Health Sciences Turkey, Şişli Etfal Training and Research Hospital, Clinic of Neurosurgery, İstanbul, Turkey
} Adem Yilmaz3

\section{Abstract}

Objective: To perform an analysis of the surgical approach choice in subaxial cervical spine (SCS) facet dislocations.

Method: The inclusion criteria were as follows: radiologically confirmed traumatic SCS facet dislocation, 18-70 years of age, stable medical condition, and isolated cervical trauma. The management scheme was based on the presence of traumatic disc herniation (TDH) and the grade of dislocation according to the Allen and Ferguson classification (AFC). In the absence of TDH, the reduction was attempted via traction under general anesthesia before surgery. In the presence of TDH, the reduction was attempted after anterior discectomy. Posterior open reduction was performed in case of an unsuccessful reduction attempt. Anterior stabilization was sufficient in AFC distractive flexion stage (DFS) 2 fractures while combined stabilization was performed in DFS 3 and 4 fractures.

Results: Thirty-two patients were included in the study. TDH was detected in 14 patients. The number of patients with DFS 2, 3, and 4 fractures was 6,18 , and 8 , respectively. Posterior open reduction was needed in 9 patients. Anterior stabilization was performed in 6 patients ( 3 with TDH, 3 without TDH) and combined stabilization was performed in 26 patients ( 11 with TDH, 15 without TDH) via 6 anterior, 7 anterior-posterior, 15 posterior-anterior, and 4 anterior-posterior-anterior approaches. Satisfactory follow-up results were achieved in radiological and neurological evaluations, and neck pain scores.

Conclusion: The treatment algorithm for subaxial facet dislocations based on DFS and TDH presence provided satisfactory results.

Keywords: Allen and Ferguson classification, decision-making, facet dislocation fracture, subaxial cervical spine, subaxial injury classification and Severity scale, traumatic disc herniation

\section{Öz}

Amaç: Bu çalışmada subaksiyel servikal omurga (SSO) faset dislokasyon fraktürlerinde cerrahi yaklaşım seçimi algoritması geliştirilmesi amaçlanmıştır.

Yöntem: Çalışmaya dahil edilme kriterleri şu şekildeydi: Radyolojik olarak gösterilmiş travmatik SSO faset dislokasyon fraktürü, 18-70 yaş, medikal olarak stabil durum ve izole servikal travma varlı̆ı. Tedavi algoritması temel olarak, travmatik disk herniasyonu (TDH) varlığına ve Allen ve Ferguson sınıflamasına (AFS) göre dislokasyon derecesine göre düzenlenmekteydi. Radyolojik incelemelerde TDH saptanmazsa, cerrahi girişim öncesinde genel anestezi altında traksiyon ile redüksiyon denenmesi yapılmaktaydı. TDH varlığında ise traksiyon denemesi öncesinde anterior diskektomi yapılmaktaydı. Eğer traksiyon ile redüksiyon girişimi başarısız olursa, posterior açık redüksiyon yapılmaktaydı. AFS'sine göre distraktive fleksiyon evre (DFE) 2 fraktürlerinde anterior stabilizasyon uygulanırken, DFE 3 ve 4 dislokasyonlarda kombine stabilizasyon yapılmaktaydı.

Bulgular: Çalışmaya 32 hasta dahil edildi. On dört hastada radyolojik incelemelerde TDH saptandı. Altı hastada DFE 2, 18 hastada DFE 3 ve 8 hastada DFE 4 faset dislokasyon fraktürü mevcut idi. Posterior açık redüksiyon 9 hastada gerekli oldu. Altı hastaya (3 TDH'si olan, 3 TDH'si olmayan) anterior stabilizasyon ve 26 hastaya (11 TDH'si olan, 15 TDH'si olmayan) kombine stabilizasyon uygulandı. Altı anterior, 7 anteriorposterior, 15 posterior-anterior ve 4 anterior-posterior-anterior yaklaşım uygulandı. Radyolojik, nörolojik değerlendirmelerde ve boyun ağrısı skorlarında tatmin edici sonuçlar elde edildi.

Sonuç: DFE ve TDH varlığına göre oluşturulan subaksiyel faset dislokasyonları için cerrahi tedavi algoritması ile başarılı sonuçlar elde edilmiştir.

Anahtar kelimeler: Allen ve Ferguson sınıflaması, faset dislokasyon fraktürü, karar verme, subaksiyel servikal omurga, subaksiyal yaralanma sınıflaması ve Şiddet ölçeği, travmatik disk hernisi

Address for Correspondence: Barış Özöner, Bahçeşehir University Faculty of Medicine, Department of Neurosurgery, İstanbul, Erzincan Binali Yıldırım University Faculty of Medicine, Department of Neurosurgery, Erzincan, Turkey

E-mail: drbarisozoner@gmail.com ORCID: orcid.org/0000-0003-0534-2766 Received: 27.06.2020 Accepted: 06.08.2020

Cite this article as: Özöner B, Aydın L, Can SM, Müslüman AM, Yılmaz A. Facet Dislocation Fractures of Subaxial Cervical Spine: A Treatment Algorithm for Surgical Approach Decision. Bagcilar Med Bull 2020;5(3):123-132

${ }^{\circ}$ Copyright 2020 by the Health Sciences University Turkey, Bagcilar Training and Research Hospital Bagcilar Medical Bulletin published by Galenos Publishing House. 


\section{Introduction}

The section of the cervical spine from C3 to C7 is called the subaxial cervical spine (SCS) $(1,2)$. The incidence of cervical spine fractures increased as a result of increased number of high energy traumas $(3,4)$. A substantial part of these fractures is localized in the SCS $(3,5,6)$. In particular, according to the literature, $44 \%$ to $62 \%$ of all cervical fractures are observed between the C5 and C7 segments $(3,5,6)$. SCS fractures can be divided into many subgroups. Facet dislocation fractures occur in case the cervical spine is subjected to severe distraction and flexion forces due to the trauma (7).

The facet dislocations are considered unstable fracture which requires surgical intervention, and decompression, reduction, and fixation are performed during procedures (8-10). Several different modalities are considered for surgical approaches such as anterior alone, posterior alone, anterior-posterior, posterior-anterior, and anteriorposterior-anterior (APA) approaches (8-12). And the choice of surgical approach in such fractures is still a debate $(11,12)$.

Reduction in facet dislocations can be performed via 3 different methods: closed, anterior, and posterior (13). Closed reduction is a commonly used method in initial management $(14,15)$. However, $22 \%$ to $40 \%$ of the facet dislocations are associated with cervical traumatic disc herniation (TDH) $(16,17)$. And, in the presence of TDH, a high risk of spinal cord compression and neurological deterioration is present in closed reduction attempts without an initial cervical discectomy (13). For this reason, the presence of disc herniation is crucial in the choice of treatment method.

The grade of facet dislocation fracture is correlated with the intensity of the trauma force that the cervical spine is subjected to (7). According to the Allen and Ferguson classification (AFC), which is based on the direction of trauma, facet dislocation fractures occur with severe distractive flexion and are divided into four stages commensurate with the severity of trauma (7). Distractive flexion stage (DFS) 1 refers to the injury of the posterior ligament complex with single facet subluxation, DFS 2 consists of unilateral facet dislocation with minimal corpus displacement, DFS 3 lesion is bilateral facet dislocation with approximately $50 \%$ corpus displacement anteriorly, and DFS 4 defines anterior displacement of the upper vertebrae over the lower vertebrae beyond the length of a corpus diameter with bilateral facet dislocation (7).
Different results are reported in the literature for anterior, posterior, and combined approaches $(8,9,11,12)$. And, the choice of surgical approach in such fractures is still a debate $(11,12)$. Therefore, in our retrospective study, we aimed to establish a management modality producing radiological and clinical optimal results in facet dislocation fractures. A treatment algorithm based on the stage of dislocation and the presence of TDH is formed.

\section{Materials and Methods}

This study was conducted following the World Medical Association Helsinki Declaration. Approval for this research was obtained from our local clinical research ethics committee. Patients who were operated between August 2014 and August 2018 were included in the study. The following were considered as the inclusion criteria in the study: radiologically confirmed traumatic SCS (C3-C7) facet dislocation fracture, 18-70 years of age, stable medical condition with Class I-III according to the American Anesthetic Association (ASA), and presence of isolated cervical trauma. And, the following were considered as the exclusion criteria in the study: unstable medical condition with ASA Class IV-V, presence of multiple trauma, and previous cervical spine operation.

Subaxial injury classification and Severity scale, based on the fracture morphology, the status of the discoligamentous complex, and neurological status, was used for treatment considerations and surgical decision (18). According to this scale, the surgical treatment decision was made in patients with a score of 5 or above, while the conservative treatment decision was made in patients with a score of 3 or below. In patients with 4 points, the decision was made according to the surgeon's choice. In all patients, cervical spinal magnetic resonance (MR) imaging and cervical spinal computed tomography (CT) were performed before surgery. Attention was paid to the osseous damage in three columns of vertebrae and the type of facet dislocation on CT images. Status of posterior ligament complex and cervical intervertebral disc and the presence of an extruded disc compressing the dural sac and nerve roots were investigated on MR images.

Operations were performed under general anesthesia. Fiberoptic intubation was performed to avoid from possible damage of hyperflexion during endotracheal intubation. Closed reduction attempt was performed under general anesthesia before the operation. Primarily, Gardner-Wells tongs (GWT) were used for closed reduction. Somatosensory evoked potentials and motor evoked potentials monitoring 
was routinely used during reduction attempts, position changes and surgical approaches to reduce the potential neurologic deterioration risk. When the closed reduction failed, a posterior open reduction was performed.

The treatment scheme formed for the management of SCS facet dislocations is shown in Figure 1. The choice of surgical approach was made according to the staging of the AFC and the presence of the TDH. Anterior stabilization (Figure 2) was performed in patients with DFS 2 fracture, while combined anterior and posterior stabilization (Figure 3) was performed in patients with DFS 3 and 4 fractures. In the presence of TDH on MR images, an initial anterior cervical discectomy was performed to prevent additional neurological injury during reduction.

In patients with $\mathrm{TDH}$, following the removal of the extruded disc material via an initial anterior discectomy, manual traction was performed by an assistant staff for reduction.
In case of successful reduction attempt, a single session anterior approach was accomplished with stabilization in patients with DFS 2 fracture. Additional posterior stabilization was performed in patients with DFS 3 and 4 fractures. In case of unsuccessful reduction attempt, the patients were taken to the prone position and posterior open reduction and stabilization were performed. Subsequently, the patients were placed in the supine position again and anterior stabilization was performed, and the approach termed APA was completed.

In patients without TDH, closed reduction was attempted with traction under general anesthesia before surgery. In case of successful reduction, anterior fusion via a single approach was performed in patients with DFS 2 dislocation, and combined (anterior and posterior) stabilization was performed in patients with DFS 3 and 4 dislocations. In the event of unsuccessful closed reduction, an initial posterior open reduction and stabilization was

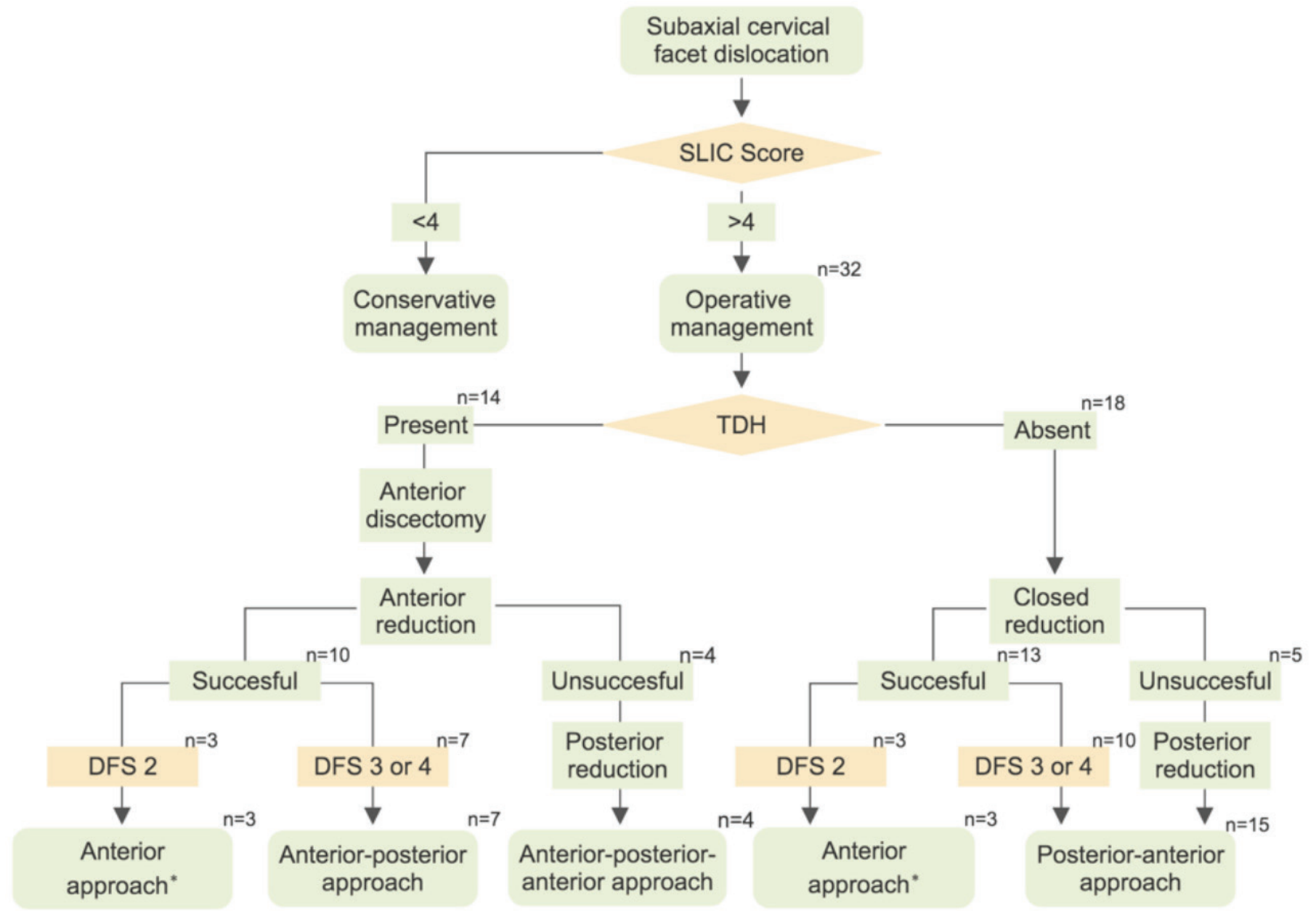

Figure 1. Treatment algorithm for the management of subaxial cervical facet dislocations

SLIC: Subaxial Cervical Spine Injury Classification, TDH: Traumatic disc herniations, DFS: Distractive flexion stage

*Anterior approach was performed in 6 patients in total 
performed. And, anterior stabilization was performed in the second stage.

A transverse incision from the midline to the medial border of the sternocleidomastoid muscle was used in the anterior approach. After vertical platysma incision,

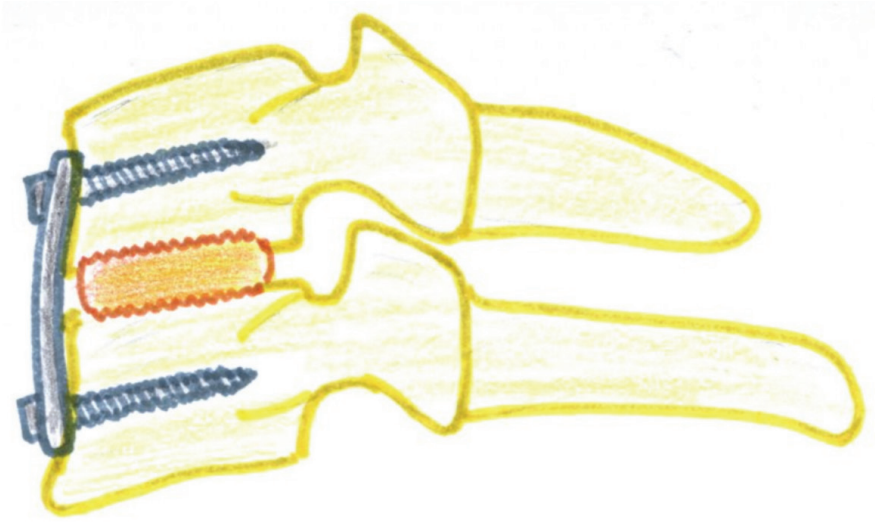

Figure 2. Illustration of anterior stabilization blunt dissection was performed to achieve a surgical corridor lateral to the trachea and esophagus, and medial to the carotid sheath. A self-retaining retractor placed underneath the musculus longus colli was used for surgical exposure. After anterior discectomy, reduction was attempted with traction in necessary cases. Anterior cervical plate systems (APSs) were used for anterior stabilization. A cervical interbody polyetheretherketone (peek) cages were placed after discectomy, and stabilization was consolidated with APSs. In patients who underwent corpectomy, tricortical osseous autograft from the iliac crest was placed in the corpectomy cavity, and stabilization was ensured with APSs.

A midline incision was planned for posterior stabilization. The paraspinal muscle dissection was performed for exposing spinous processes, laminae, and facets (lateral masses), and a self-retaining retractor was placed. In case of unsuccessful reduction via manual traction, the apex of the superior articular process of the inferior facet was resected using a high-speed drill to release the locked facets. Short
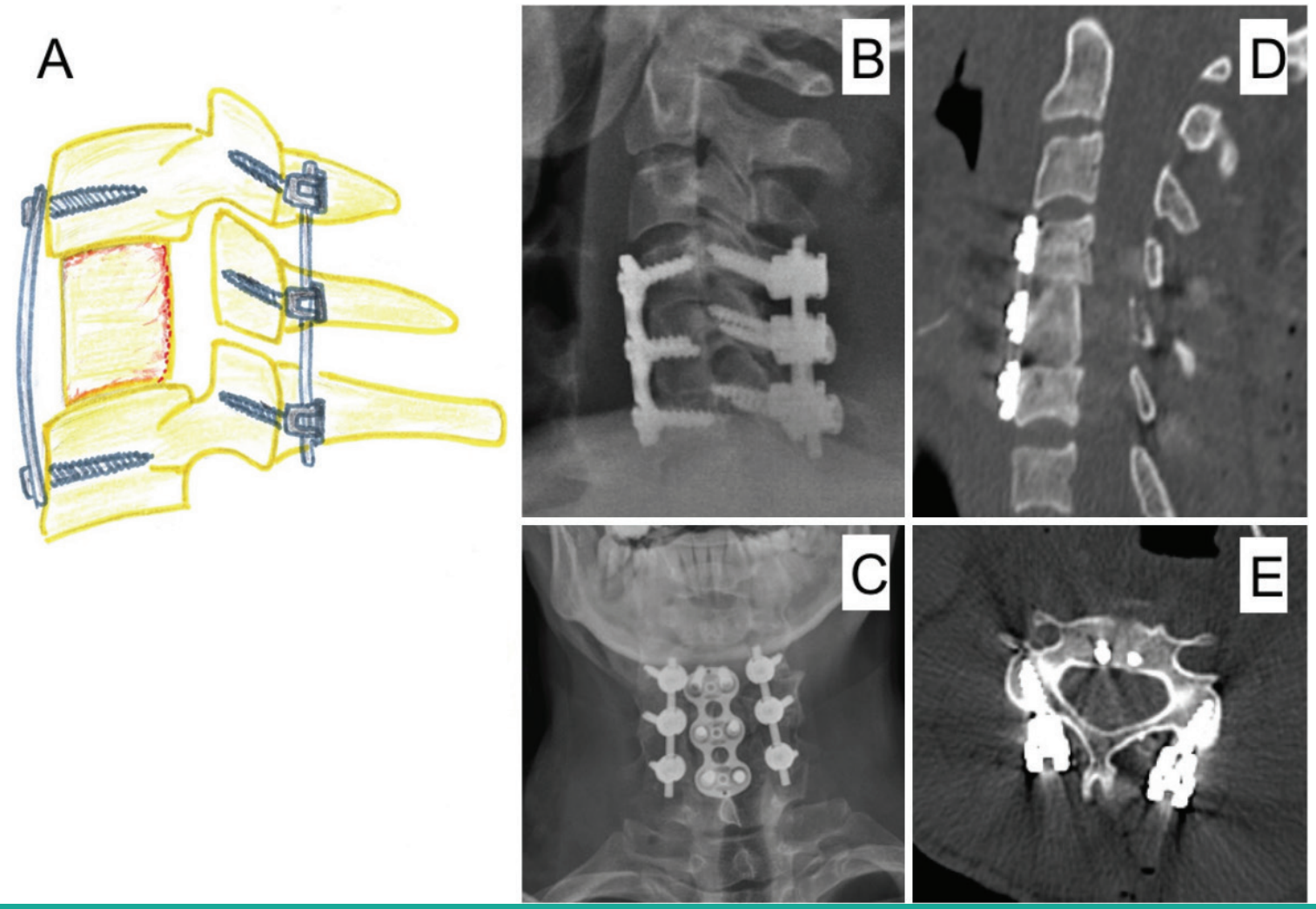

Figure 3. Illustration of combined stabilization

A. Illustration of combined anterior and posterior stabilization

B. Lateral view of X-ray showing sagittal alignment after combined stabilization

C. Mid-sagittal image of computed tomography (CT)

D. Anterior-posterior view of X-ray

E. Axial CT image showing anterior corpus and lateral mass screws 
segmental fixation, using lateral mass screws at C3-C6, and pedicle screws at $\mathrm{C} 7$ and $\mathrm{T} 1$ vertebrae, was carried out in the reduced position.

Patients were called for a control examination in the first, third, and sixth months, first year, and subsequent years after discharge. Radiological and clinical records were analyzed to evaluate the results of the treatment. Evaluation of the neurological status of the patients was made using the American Spinal Injury Association (ASIA) Impairment scale. Changes in neck pain were evaluated using the Visual Analog scale (VAS).

Radiological evaluation was performed via lateral and anteroposterior cervical spine radiographs at each control examination, and via CT scan at 3 months, 6 months, 1 year, and subsequent years control visits. In the radiological follow-up, angulation of the upper endplate of the upper vertebra with the lower endplate of the lower vertebra, evaluated in sagittal imaging, was determined as traumatic kyphosis angle (Figure 4). The trabecular bone formation between the graft material and vertebral corpus and no sign of failure in implants were accepted as successful fusion during follow-up.

\section{Statistical Analysis}

Statistical analysis was performed using IBM Statistical Package for Social Sciences (SPSS) Statistics for Windows, version 25.0 (IBM Corp., Armonk, New York, USA).

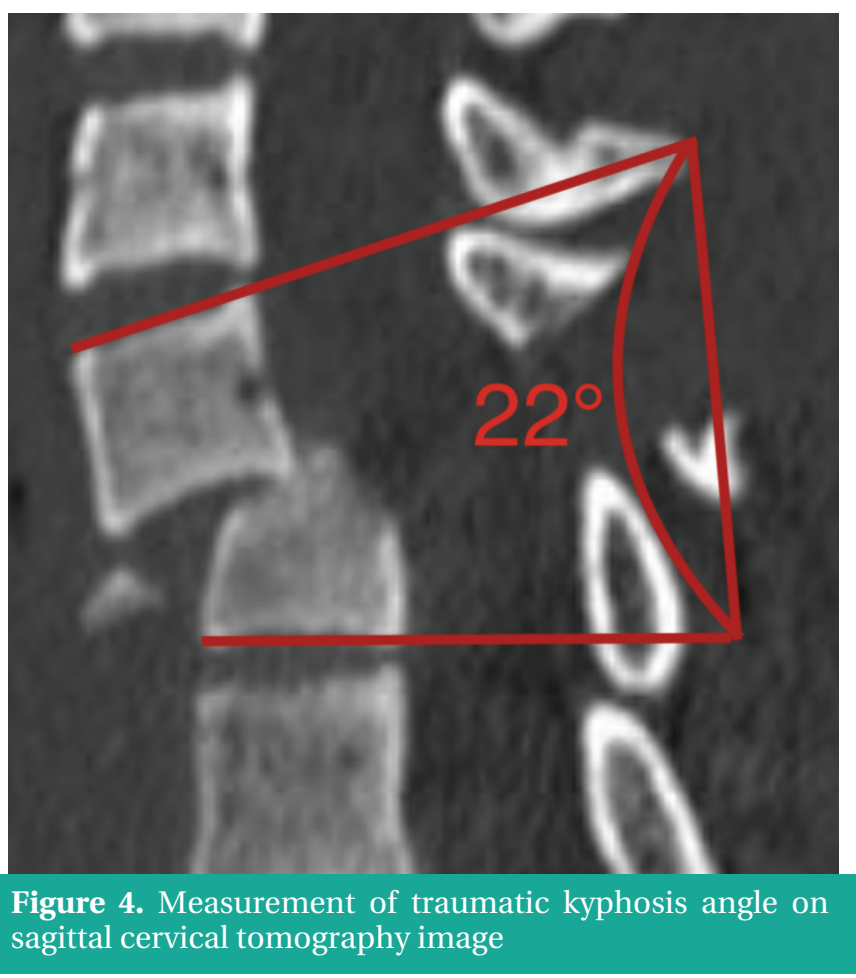

Numerical variables were summarized as mean and standard deviation. Numerical variables were assessed using independent samples t-test. A p value of $<0.05$ was considered significant for all statistical analyses.

\section{Results}

The characteristics of patients at admission were summarized in Table 1. A total of 32 (8 women and 24 men) patients were included in the study. The average age was $37.4 \pm 16.1$ years, and the age distribution was 18-58 years. The most common cause of trauma was fall $(n=20,62.5 \%)$, followed by traffic accidents $(n=10$, $31.25 \%)$. Unilateral and bilateral facet dislocation was observed in 6 and 26 patients, respectively. In the staging according to AFC, most of the patients had DFS 3 dislocation ( $\mathrm{n}=18,56.2 \%)$, followed by DFS 4 fracture $(\mathrm{n}=8,25 \%)$. Neurological status evaluated according to ASIA Impairment scale revealed that 8 (25\%) patients had a complete neurological injury (ASIA grade A), 20 (62.5\%) patients had an incomplete neurological injury (ASIA grade B-C-D) and 4 patients were neurologically intact (ASIA grade E). Fractures were most frequently observed at C6-C7 level ( $\mathrm{n}=15,46.9 \%)$ followed by C5-C6 level $(\mathrm{n}=10,31.3 \%)$. On cervical vertebral MR images, TDH was detected in 14 (43.7\%) patients.

\begin{tabular}{lll}
\multicolumn{2}{l}{ Table 1. Characteristics of patients at admission } \\
Total number & & 32 \\
Age (Mean \pm SD) & & $37.4 \pm 16.1$ \\
Gender & Female & $8(25 \%)$ \\
& Male & $24(75 \%)$ \\
Trauma mechanism & Fall from high & $20(62.5 \%)$ \\
& Traffic accidents & $10(31.25 \%)$ \\
Severity of dislocation & Jumping into shallow water 2 & $2(6.25 \%)$ \\
(AFC) & DFS 3 & $6(18.8 \%)$ \\
& DFS 4 & $18(56.2 \%)$ \\
& Grade A & $8(25 \%)$ \\
Neurological status & Grade B & $8(25 \%)$ \\
(ASIA) & Grade C & $5(15.6 \%)$ \\
& Grade D & $6(18.8 \%)$ \\
& Grade E & $9(28.1 \%)$ \\
& C3-C4 & $4(12.5 \%)$ \\
Fracture level & C4-C5 & $1(3.1 \%)$ \\
& C5-C6 & $4(12.5 \%)$ \\
& C6-C7 & $10(31.25 \%)$ \\
& C7-T1 & $15(46.9 \%)$ \\
& & $2(6.25 \%)$ \\
\hline
\end{tabular}

SD: Standard deviation, AFC: Allen and Ferguson classification, DFS: Distractive flexion stage, ASIA: American Spinal Injury Association 
The reduction was attempted with traction under general anesthesia before the operation in 18 patients without TDH. Closed reduction was successful in 13 of these patients. In 3 patients with DFS 2 dislocation, single session anterior stabilization was performed in the supine position. In the other 10 patients with DFS 3 or 4 dislocations, combined anterior and posterior stabilization was performed. In 5 patients for whom reduction was unsuccessful, posterior open reduction was performed via an initial posterior approach and was maintained by the combined posterior and anterior stabilization.

An initial anterior cervical discectomy was performed in 14 patients with TDH on MR images. Subsequently, the reduction was attempted by manual traction performed by an assistant staff during surgery. The reduction was achieved in 10 of these patients. Single session anterior stabilization was performed in 3 with DFS 2 fracture of these 10 patients. In the other 7 patients with DFS 3 or 4 fractures, combined anterior and posterior stabilization was performed. In 4 patients with unsuccessful reduction attempt after discectomy during the anterior approach, the patients were switched to the prone position, and posterior open reduction and stabilization were performed. Subsequently, the patients were placed in the supine position again for anterior stabilization and the combined anterior and posterior stabilization was accomplished.
The methods applied during the choice of approach for patients are summarized in Figure 1. Also, the number of approaches selected for patients is shown in Figure 1. In total, single anterior stabilization was performed in 6 patients, and combined anterior and posterior stabilization was performed in 26 patients. Out of the patients who underwent combined stabilization, 7 were performed initial anterior subsequent posterior (AP) approach, 15 were performed initial posterior subsequent anterior (PA) approach, and 4 were performed APA approach. Reduction attempt with manual traction was successful in 23 patients, while the posterior open reduction was necessary for 9 patients (5 with DFS 3 dislocation; 4 with DFS 4 dislocation). Preoperative and postoperative radiological images of a sample patient were presented in Figure 5.

Operative and postoperative data of patients were summarized in Table 2. The mean operation time was longer, and the mean amount of bleeding was more in the APA approach than others. The average length of hospital stay was $24.3 \pm 29.5$ days. The hospital stay was significantly longer in patients with complete neurological injury. This period was $12.3 \pm 12.1$ days in patients with incomplete medulla spinalis injury.

During hospitalization, pulmonary embolism (PE) was observed in 3 patients (2 with DFS 4 dislocation, and 1 with DFS 3 dislocation) and diabetes insipidus (DI) was
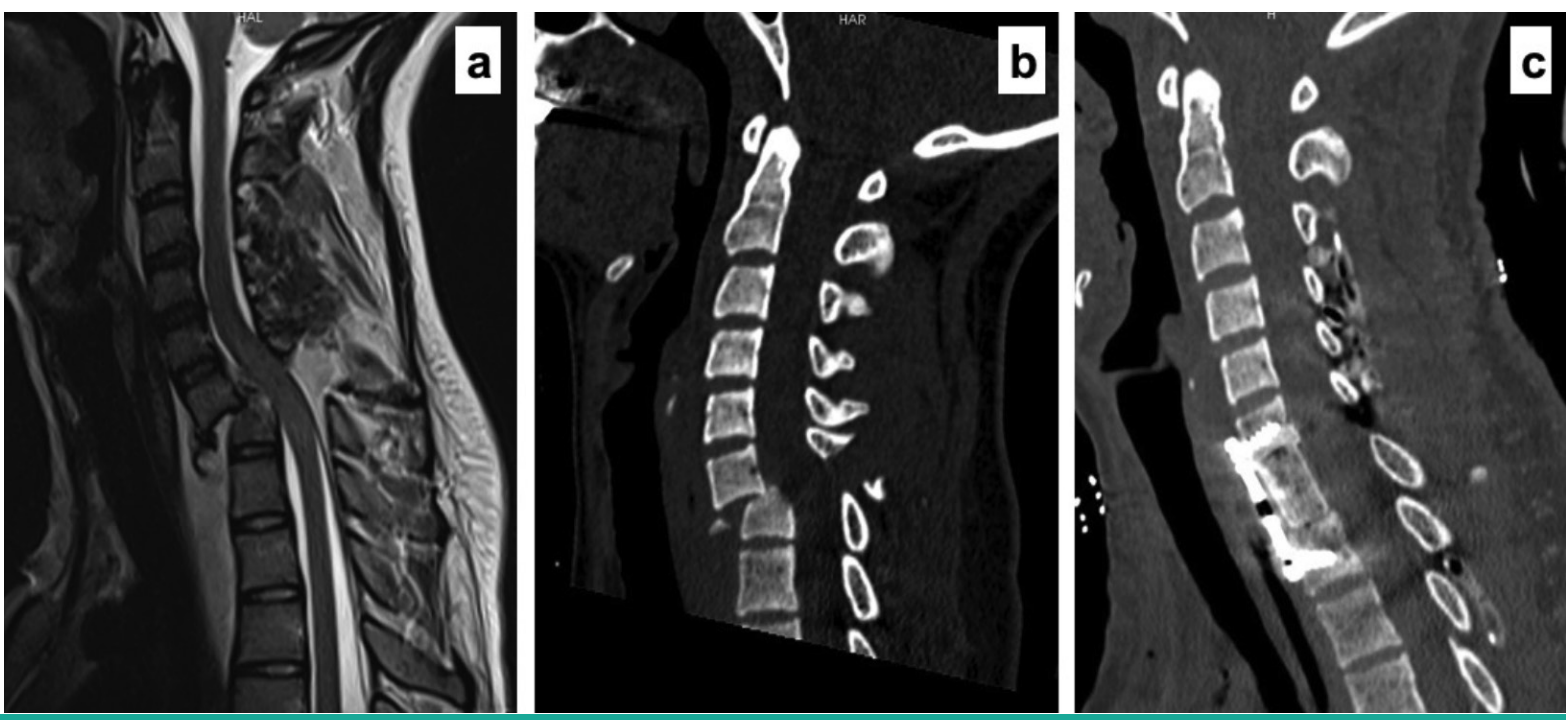

Figure 5. An illustrative case of distractive flexion stage 4 subaxial cervical facet dislocation

A. Preoperative sagittal T2-weighted magnetic resonance image

B. Preoperative sagittal cervical computed tomography (CT) image

C. Sagittal cervical CT image after reduction and combined anterior and posterior stabilization

CT: Computed tomography 
observed in 1 patient. PE was successfully treated with anticoagulant medication in all three patients. DI was defined on the $25^{\text {th }}$ day after operation in a patient with C6C7 DFS 4 fracture who was treated with a PA approach and resolved with medical treatment. A patient with C5-C6 DFS 4 dislocation with ASIA grade A neurological status suffered from respiratory failure due to intercostal muscle paralysis and was lost due to the septic shock during intensive care unit treatment.

General follow-up data of patients were summarized in Table 3 . The mean follow-up period was $38.4 \pm 11.5$ (Distribution: 15-64) months. Neck pain was evaluated with VAS score, the averages were $7.4 \pm 1.9$ before the operation and $1.7 \pm 0.6$ at end of follow-up. Significant improvement was observed

$\begin{array}{ll}\text { Table 2. Operative and postoperative data of patients } \\ \text { Operation time (min) } \\ \text { Anterior approach } & 121 \pm 47 \\ \text { Anterior - posterior approach } & 197 \pm 51 \\ \text { Posterior - anterior approach } & 189 \pm 39 \\ \text { Anterior - posterior - anterior approach } & 257 \pm 53 \\ \text { Blood loss (mL) } & \\ \text { Anterior approach } & 123 \pm 49 \\ \text { Anterior - posterior approach } & 190 \pm 55 \\ \text { Posterior - anterior approach } & 203 \pm 56 \\ \text { Anterior - posterior - anterior approach } & 305 \pm 89 \\ \text { Hospitalization duration (days) } & 24.3 \pm 29.5 \\ \text { Complete injury (ASIA A) } & 56.3 \pm 40.9 \\ \text { Incomplete injury (ASIA B-C-D-E) } & 12.3 \pm 12.2 \\ \text { Complication } & \\ \text { Pulmonary embolism } & 3(9.4 \%) \\ \text { Diabetes insipidus } & 1(3.1 \%) \\ \text { Mortality } & 1(3.1 \%)\end{array}$

ASIA: American Spinal Injury Association

Table 3. Data of patients during follow-up in all examinations after treatment compared to the preoperative period $(\mathrm{p}<0.001)$. Preoperative radiological examinations revealed kyphotic deformity in 20 patients. The mean angle of the deformity was $20.5 \pm 6.3^{\circ}$ kyphosis in the preoperative period. This angle was observed as $3.3 \pm 2.5^{\circ}$ lordosis at the end of follow-up. No neurological deterioration was observed after intervention in 24 patients with an incomplete injury. Various levels of neurological improvement were observed in patients with an incomplete injury, but no neurological improvement was observed in all 8 patients with complete medulla spinalis injury (ASIA grade A). The osseous fusion rate was $87 \%$ after 3 months, and $100 \%$ after one-year follow-up.

Neurological status follow-up data of patients stratified according to the severity of dislocation (AFC) were shown in Table 4. The worst neurological condition was present in patients with DFS 4 fracture and all patients were classified as ASIA grade A. And the best neurological condition was observed in patients with DFS 2 fracture, besides 4 of 6 (66\%) patients were presented without any neurological deficits. Worst neurological status outcome was observed in the subgroup of patients with DFS 4 fracture. No neurological improvement was observed in all patients of this subgroup during follow-up. However, a favorable neurological condition course was observed in patients with DFS 2 fracture, all of the patients ended up with ASIA grade $\mathrm{E}$ at the end of follow-up.

Data for TDH appearance, posterior open reduction requirement, and chosen surgical approach results of patients stratified AFC were summarized in Table 5. While TDH presence rate was $44 \%$ in the present cohort series, this rate was $50 \%, 56 \%$, and $13 \%$ in DFS 2, 3, and 4 subgroups, respectively. The success rate of reduction attempt with traction was $100 \%$ in patients with DFS 2 fracture, while the

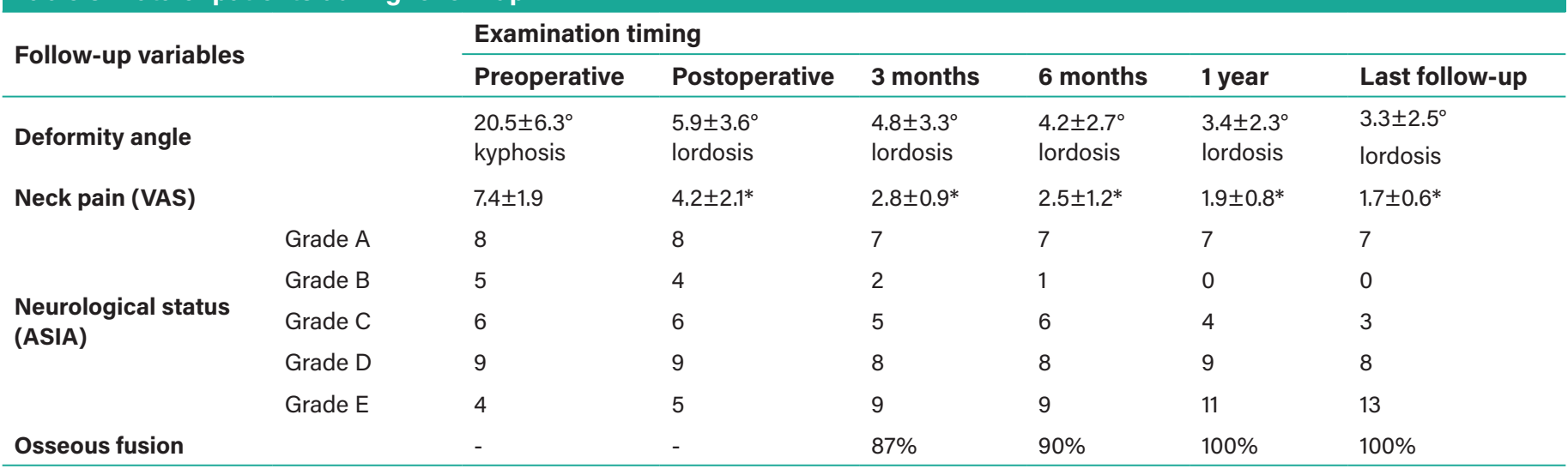

*: p<0.001 (compared with the preoperative period using Student's t-test Calculator), VAS: Visual Analog scale, ASIA: American Spinal Injury Association 
posterior open reduction was required in $33 \%$ and $55 \%$ of patients in the DFS 3 and DFS 4 subgroups, respectively. Consequently, the anterior approach was performed in all patients with DFS 2 fracture; and the PA approach was the most common intervention in DFS 3 (44\%) and DFS 4 (87\%) subgroups.

\section{Discussion}

In the present study, satisfactory clinical and radiological results were obtained in the treatment of facet dislocation of the SCS with surgical approach selection according to the severity of the facet dislocation graded by AFC, and with reduction attempt with manual traction arranged according to TDH presence. Performing combined stabilization in DFS 3 and 4 fractures, relatively higher stages based on AFC, and anterior stabilization in stage 2 fractures, and carrying out an anterior discectomy in the presence of TDH before reduction attempt via traction provided appropriate outcomes. In case of unsuccessful closed reduction, proper alignment was achieved via posterior open reduction without any neurological deterioration occurrence.

The epidemiology of spine traumas shows that $44 \%$ to $62 \%$ of all cervical spine fractures are localized between $\mathrm{C} 5$ and C7 levels $(3,5,6)$. In our series, the ratio of C5-C6 and C6-C7 fractures among the five segments was $78.1 \%$. The male/ female ratio in spinal fractures was observed between 1.6 and 3 in the literature (3-5). This rate was found 3 in our study. The most common cause of spinal fractures is defined as falling from height, followed by traffic accidents (3-5). Similar results were obtained in our series.

The choice of surgical method is determined according to the type of facet dislocation, the neurological status, and the presence of disc herniation $(8,19)$. Patients with no or incomplete neurological injury are more likely to recover than patients with a complete injury (20). Our series supports these data. At a one-year follow-up, no neurological improvement was observed in patients with complete injury (ASIA A), while other patients (ASIA B to E) improved at different rates. Therefore, maintaining the existing neurological status is important in the choice of treatment method. However, one of the potentials accompanying subaxial facet dislocation is TDH. In the literature, the rate of TDH presence in subaxial facet dislocation patients was reported between $22 \%$ and $40 \%(16,17)$. Reduction of dislocation in the presence of TDH can provoke the existing injury and worsen the neurological status of the patient (8). Therefore, if present, the extruded disc material was removed via discectomy before the reduction attempt in our series. Another factor influencing the management

Table 4. Neurological status follow-up data of patients stratified according to the grade of dislocation (AFC)

\begin{tabular}{|c|c|c|c|c|c|c|c|}
\hline \multirow{2}{*}{$\begin{array}{l}\text { Dislocation severity } \\
\text { (AFC) }\end{array}$} & \multirow{2}{*}{$\begin{array}{l}\text { Neurological } \\
\text { status (ASIA) }\end{array}$} & \multicolumn{6}{|c|}{ Examination timing } \\
\hline & & Preop & Postop & 3 months & 6 months & 1 year & Last follow-up \\
\hline \multirow{2}{*}{ DFS 2} & Grade D & 2 & 1 & - & - & - & - \\
\hline & Grade $\mathrm{E}$ & 4 & 5 & 6 & 6 & 6 & 6 \\
\hline \multirow{4}{*}{ DFS 3} & Grade B & 5 & 4 & 2 & 1 & - & - \\
\hline & Grade C & 6 & 6 & 5 & 6 & 4 & 3 \\
\hline & Grade D & 7 & 8 & 8 & 8 & 9 & 8 \\
\hline & Grade E & - & - & 3 & 3 & 5 & 7 \\
\hline DFS 4 & Grade A & 8 & 8 & $7^{*}$ & 7 & 7 & 7 \\
\hline
\end{tabular}

AFC: Allen and Ferguson classification, ASIA: American Spinal Injury Association, DFS: Distractive flexion stage, *: One patient died during follow-up, Preop: Preoperative, Postop: Postoperative

Table 5. TDH appearance, open reduction requirement, and chosen surgical approach results of patients stratified according to the grade of dislocation (AFC)

\begin{tabular}{|c|c|c|c|c|c|c|c|c|}
\hline \multirow{2}{*}{$\begin{array}{l}\text { Dislocation } \\
\text { severity (AFC) }\end{array}$} & \multicolumn{2}{|c|}{ TDH } & \multicolumn{2}{|c|}{$\begin{array}{l}\text { Reduction attempt } \\
\text { with traction }\end{array}$} & \multicolumn{4}{|c|}{$\begin{array}{l}\text { Surgical } \\
\text { approach }\end{array}$} \\
\hline & Present & Absent & Successful & Unsuccessful & Anterior & AP & APA & PA \\
\hline DFS 2 & 3 & 3 & 6 & - & 6 & - & - & - \\
\hline DFS 3 & 10 & 8 & 13 & 5 & - & 6 & 4 & 8 \\
\hline DFS 4 & 1 & 7 & 4 & 4 & - & 1 & - & 7 \\
\hline
\end{tabular}

AFC: Allen and Ferguson classification, TDH: Traumatic disc herniation, AP: Anterior-posterior, APA: Anterior-posterior-anterior, PA: Posterior-anterior, DFS: Distractive flexion stage 
scheme in our series is the severity of the fracture. The severity of the facet dislocation affects the success of the procedure performed during the treatment. AFC is used for staging the fracture in our series (7). According to this classification, while anterior stabilization was sufficient in DFS 2 fractures with unilateral facet dislocation and listhesis below $50 \%$ of the corpus distance, combined anterior and posterior stabilization was performed in DFS 3 or 4 fractures with bilateral facet dislocation and listhesis above $50 \%$ of the corpus distance. The third factor affecting treatment management in our series was whether the reduction with traction was successful or not. In case of an unsuccessful attempt, an open reduction was performed with the posterior approach. In the scheme designed to obtain an effective surgical intervention using these factors, anterior, AP, PA, and APA approaches have been performed.

Management recommendations for facet dislocations of the SCS have been previously reported $(8,21)$. Previous publications indicated closed reduction with manual traction in the first phase of treatment $(8,21)$. The successfully closed reduction rate was reported as $80.5 \%$ (33/41 patients) by Reindl et al. (21) Also, open reduction was performed with an anterior approach in the other 8 patients. However, neurological deterioration was observed in 1 patient of this series (21). In another series by Jiang et al. (8), closed reduction was successful in 22 (42.3\%) of 52 patients and no neurological deterioration occurred in any patient. In our series, the success rate of closed reduction was $68.7 \%$ (22/32 patients) and no new neurological deficits were observed due to reduction.

Posterior open reduction was performed in cases where the reduction with traction was unsuccessful in our series. Posterior open reduction was also implemented by Nakashima et al. (17). In 40 patients of facet dislocation accompanied with TDH, posterior open reduction and posterior arthrodesis were performed without any new neurological deficits (17). However, 25 (62.5\%) of patients in this series had a complete neurological injury (ASIA A) (17). The complete injury rate was lower $(25 \%)$ and the posterior open reduction was only performed in the absence of TDH in our series. To reduce the risk of a new neurological deficit, the extruded material was removed by discectomy before reduction attempt in the presence of TDH. In another study by Park et al. (22), in which open reduction and pedicle screw fixation were performed in a single session posterior approach, disc material was excised with a postero-lateral approach in the presence of
TDH.

Anterior approaches are preferable for the removal of the disc material in the presence of TDH $(10,23)$. Feng et al. (23) applied the combined approach consisting of anterior decompression and grafting before posterior stabilization in their series with 21 patients with lower cervical facet dislocation accompanied by TDH. In this series, improvement in kyphotic deformity and satisfactory results in neurological status were obtained, but a significant decrease in neck mobility developed due to the length of posterior segmental stabilization (23). In a study by Jiang et al. (8), an initial cervical discectomy was advised in the treatment method of lower cervical facet dislocations in the presence of TDH. Similar to our series, the reduction was attempted with manual traction after discectomy. In cases of successful reduction, the anterior approach was considered sufficient (10). However, the stage of fracture dislocation was not taken into account in this series (10). In our series, the anterior approach was sufficient in unilateral facet dislocation with listhesis shorter than $50 \%$ corpus distance (DFS 2 fracture), whereas the combined anterior and posterior stabilization was preferred in DFS 3 or 4 dislocations. In case of unsuccessful closed reduction, Jiang et al. (8) performed an APA approach similar to our series with posterior open reduction and subsequently anterior stabilization.

In the anterior approach suggested by Liu and Zhang (13), the success rate was $82 \%$ for the reduction attempt using traction with Caspar pins. In our study, the overall success rate of the reduction attempt with traction was $72 \%$. While this rate was $71.4 \%$ in the manual traction performed after anterior discectomy in patients with $\mathrm{TDH}$, this rate was $72.2 \%$ in the traction performed using GWT before the operation in patients without TDH. Liu and Zhang (13) suggested performing anterior facetectomy in case traction with Caspar pins did not provide successful reduction. And they reported a $100 \%$ reduction rate after facetectomy (13). In our study, if the reduction was not achieved with traction, a posterior partial facetectomy was performed. Similarly, a $100 \%$ reduction was achieved after facetectomy. However, to provide sufficient stabilization, Liu and Zhang (13) used anterior corpus screw plus anterior pedicle screw and plate fixation.

\section{Conclusion}

A management chart for facet dislocation fractures of the SCS is advised in the present study. As the result of the interventions applied according to this chart, radiological 
and clinical satisfactory results were obtained. The proposed algorithm for facet dislocations can be effective when the management is planned according to the grade of the dislocation and the presence of TDH.

\section{Ethical Statements}

All procedures were performed following the ethical standards of the 1964 Helsinki declaration and its later amendments or comparable ethical standards. Approval for this research was obtained from our local clinical research ethics committee.

\section{Ethics}

Ethics Committee Approval: Approval of this research eas obtained from Erzincan Binali Ylldırım University Clinical Research Ethics Committee (approval no: 05/28, date: 29/04/2020).

Informed Consent: Written informed consent was obtained from the participants.

Peer-review: Externally peer-reviewed.

\section{Authorship Contributions}

Concept: B.Ö., A.M.M., A.Y., Design: B.Ö., S.M.C., A.Y., Data Collection or Processing: L.A., S.M.C., Analysis or Interpretation: L.A., A.M.M., Literature Search: L.A., A.M.M., Writing: B.Ö., L.A.

Conflict of Interest: No conflict of interest was declared by the authors.

Financial Disclosure: The authors declared that this study received no financial support.

\section{References}

1. Oh SH, Perin NI, Cooper PR. Quantitative three-dimensional anatomy of the subaxial cervical spine: Implication for anterior spinal surgery. Neurosurgery 1996;38(6):1139-1144.

2. Lopez AJ, Scheer JK, Leibl KE, Smith ZA, Dlouhy BJ, Dahdaleh NS. Anatomy and biomechanics of the craniovertebral junction. Neurosurg Focus 2015;38(4):E2.

3. Leucht P, Fischer K, Muhr G, Mueller EJ. Epidemiology of traumatic spine fractures. Injury 2009;40(2):166-172.

4. Pickett GE, Campos-benitez M, Keller JL, Duggal N. epidemiology of traumatic spinal cord injury in canada epidemiology of traumatic spinal cord injury in canada. Spine (Phila Pa 1976) 2015;31(7):799805.

5. Wang H, Zhang Y, Xiang Q, WangX, LiC, Xiong H, et al. Epidemiology of traumatic spinal fractures: Experience from medical universityaffiliated hospitals in Chongqing, China, 2001-2010: Clinical article. J Neurosurg Spine 2012;17(5):459-468.

6. Ryan MD, Henderson JJ. The epidemiology of fractures and fracture-dislocations of the cervical spine. Injury 1992;23(1):38-40.
7. Allen BL, Ferguson RL, Lehmann TR, O’Brien RP. A mechanistic classification of closed, indirect fractures and dislocations of the lower cervical spine. Spine (Phila Pa 1976) 1982;7(1):1-27.

8. Jiang X, Yao Y, Yu M, Cao Y, Yang H. Surgical treatment for subaxial cervical facet dislocations with incomplete or without neurological deficit : a prospective study of 52 cases. Med Sci Monit 2017;23:732740 .

9. Wang B, Zhu Y, Jiao Y, Wang F, Liu X, Zhu H, et al. A new anteriorposterior surgical approach for the treatment of cervical facet dislocations. J Spinal Disord Tech 2014;27(3):E104-109.

10. Du W, Wang C, Tan J, Shen B, Ni S, Zheng Y. Management of subaxial cervical facet dislocation through anterior approach monitored by spinal cord evoked potential. Spine (Phila Pa 1976) 2014;39(1):4852.

11. Hadley MN, Walters BC, Grabb PA, Oyesiku NM, Przybylski GJ, Resnick DK, et al. Treatment of subaxial cervical spinal injuries. Neurosurgery 2002;50(3 Suppl):S156-165.

12. Lins CC, Prado DT, Joaquim AF. Surgical treatment of traumatic cervical facet dislocation: anterior, posterior or combined approaches? Arq Neuropsiquiatr 2016;74(9):745-749.

13. Liu K, Zhang Z. A novel anterior-only surgical approach for reduction and fixation of cervical facet dislocation. World Neurosurg 2019;128:e362-e369.

14. Vital JM, Gille O, Sénégas J, Pointillart V. Reduction technique for uni- and biarticular dislocations of the lower cervical spine. Spine (Phila Pa 1976) 1998;23:949-954.

15. Gelb DE, Hadley MN, Aarabi B, Dhall SS, Hurlbert RJ, Rozzelle CJ, et al. Initial closed reduction of cervical spinal fracture-dislocation injuries. Neurosurgery 2013;72(Suppl 2):73-83.

16. Rizzolo SJ, Piazza MR, Cotler JM, Balderston RA, Schaefer D, Flanders A. Intervertebral disc injury complicating cervical spine trauma. Spine (Phila Pa 1976) 1991;16(6 Suppl):S187-189.

17. Nakashima H, Yukawa Y, Ito K, Machino M, El Zahlawy H, Kato F. Posterior approach for cervical fracture-dislocations with traumatic disc herniation. Eur Spine J 2011;20(3):387-394.

18. Vaccaro AR, Hulbert RJ, Patel AA, Fisher C, Dvorak M, Lehman RA, et al. The subaxial cervical spine injury classification system: A novel approach to recognize the importance of morphology, neurology, and integrity of the disco-ligamentous complex. Spine (Phila Pa 1976) 2007;32(21):2365-2374.

19. Nassr A, Lee JY, Dvorak MF, Harrop JS, Dailey AT, Shaffrey CI, et al. Variations in surgical treatment of cervical facet dislocations. Spine (Phila Pa 1976) 2008;33(7):E188-193.

20. Yisheng W, Fuying Z, Limin W, Junwei L, Guofu P, Weidong W. First aid and treatment for cervical spinal cord injury with fracture and dislocation. Indian J Orthop 2007;41(4):300-304.

21. Reindl R, Ouellet J, Harvey EJ, Berry G, Arlet V. Anterior reduction for cervical spine dislocation. Spine (Phila Pa 1976) 2006;31(6):648652.

22. Park JH, Roh SW, Rhim SC. A single-stage posterior approach with open reduction and pedicle screw fixation in subaxial cervical facet dislocations. J Neurosurg Spine 2015;23(1):35-41.

23. Feng G, Hong Y, Li L, Liu H, Pei F, Song Y, et al. Anterior decompression and nonstructural bone grafting and posterior fixation for cervical facet dislocation with traumatic disc herniation. Spine (Phila Pa 1976) 2012;37(25):2082-2088. 